\title{
HUMAN PULMONARY INFECTIONS WITH BOVINE AND ENVI- RONMENT (ATYPICAL) MYCOBACTERIA IN JOS, NIGERIA
}

\author{
*J.D. MAWAK, N.E. GOMWALK ${ }^{1}$, C.S.S. BELLO ${ }^{1}$ AND Y.T. KANDAKAI-OLUKEMI ${ }^{1}$ \\ Departments of Microbiology and ${ }^{1}$ Medical Microbiology, University of Jos, \\ P.M.B. 2084, Jos, Nigeria.
}

\begin{abstract}
SUMMARY
Objectives: To examine sputum specimens from patients with persistent bronchopulmonary disorders for mycobacterium species and to characterize the recovered isolates with a view to determining the extent of involvement of environmental mycobacteria in pulmonary infections.

Design: Analytical study using standard microscopy, culture and biochemical test for the identification of mycobacterium species.
\end{abstract}

Setting: Jos University Teaching Hospital (JUTH) and 2 referral hospitals: Plateau Specialist Hospital and Evangelical Churches of West Africa (ECWA) Evangel Hospital in Jos, Nigeria.

Participants: Three hundred and twenty nine (329) volunteer new patients seen at the chest clinic and general out patient departments with broncho-pulmonary disorders. Patients already on anti-tuberculosis were excluded from the study.

Interventions: Subjects were administered antituberculosis drugs and or other treatment regimes after proper diagnosis

Results: Sixty-five (65) mycobacterial isolates were obtained and differentiated into human tubercle bacilli, bovine and or environmental (atypical) mycobacteria on the basis of nine identification tests. Of the 65 mycobacterial isolates subjected to the tests, $40(61.54 \%)$ were identified as mycobacterium tuberculosis, $10(15.38 \%)$ as $M$. bovis and $15(23.08 \%)$ as environmental mycobacteria. Among the environmental group, 9 (20.69\%) were classified as M. avium 3 (3.45\%) each as M. kansasi and $M$. fortuitum.

Conclusions: The study confirms the involvement of bovine and environmental mycobacteria in pulmonary infections. This may be related to the rising prevalence of HIV/AIDS globally. The need for adequate bacteriological analysis in current-day diagnosis of pulmonary tuberculosis in indicated.

Keywords: Environmental mycobacterium, pulmonary tuberculosis, sputum, Nigeria.

\section{INTRODUCTION}

Environmental (Atypical or "anonymous") mycobacteria have been documented to be involved in human pulmonary infections in both developed and developing countries ${ }^{1,2,3,4,5}$. Incidence rates of between $2-20 \%$ for atypical mycobacteriosis have been reported from various parts of the world ${ }^{5,6,7}$. In a World Health Organisation assisted survey of various parts of Nigeria in 1963, a 6\% National Incidence rate of atypical mycobacteria was reported $^{1}$. Also, in Lagos, Nigeria, Idigbe et $\mathrm{al}^{5}$ reported an incidence rate of $11 \%$ for atypical mycobacteriosis. The only two reports of the involvement of bovine mycobacteria in human pulmonary infections in Nigeria are those of Alhaji and Schnurrenberger ${ }^{8}$ who documented a $10 \%$ incidence rate in four of the then Northern States of the country and Idigbe et $\mathrm{al}^{5}$ documented a $3.9 \%$ incidence rate in Lagos.

In the last few decades, the incidence of classical tuberculosis has been on the increase alongside tuberculosis-like disease caused by environmental mycobacteria. The apparent increase in the frequency of isolation of these mycobacteria from clinical specimens and the mounting evidence of their aetiology in severe pulmonary diseases in severe pulmonary diseases in man is currently generating concern as far as the accurate diagnosis and treatment of classical tuberculosis is concerned. Clinically and radiologically, the pulmonary diseases produced by environmental strains are indistinguishable from classical pulmonary tuberculosis, whereas the two diseases present fundamental differences in their epidemiology, management and prognosis ${ }^{5}$. It is therefore important that clinicians and bacteriologists appreciate the fact that not all Acid Fast Bacillus (AFB) found in sputum are Mycobacterium tuberculosis.

This paper reports the results of the differentiation of 65 mycobacteria isolates obtained from patients in Jos, Nigeria.

\footnotetext{
* Author for correspondence
} 


\section{MATERIALS AND METHODS Study Population}

Sputum samples were collected from three hundred and twenty-nine (329) new patients seen at the Chest Clinic and general out-patient department of Jos University Teaching Hospital (JUTH), Plateau Specialist Hospital and Evangelical Churches of West Africa (ECWA) Evangel Hospital all in Nigeria with broncho-pulmonary features including fever, loss of weight, persistent productive cough lasting for $\geq 4$ weeks, haemoptysis and abnormal chest X-ray among others. The patients were screened for AFB in their sputum. The first sputum samples were collected on the first day of reporting to the hospital; thereafter first early morning sputum specimens were collected for 2 consecutive days.

\section{Bacteriological Analysis of Sputum Samples}

The sputum samples were examined by microcopy and culture. The samples were first digested and concentrated by Petroff's method ${ }^{9}$. Smears of the final deposits from the various specimens were stained by the Ziehl-Neelsen (Z-N) method and examined under oil immersion using a binocular light microscope.

Loopfuls of the various deposits were also evenly spread on to the surfaces of a pair of LowensteinJensen (L-J) slopes, incubated at $37^{\circ} \mathrm{C}$ and observed daily on the first week and subsequently twice a week for 8 weeks. Slopes without visible growth after 8 weeks were discarded and recorded as negative, while slopes showing mycobacterial growth were recorded as positive. All such growths were checked for acid fast properties by Z-N microscopy. A case was taken to be positive when visible growth of pure colonies of AFB was obtained from at least one of the 3 sputum samples per case.

\section{Classification of Isolates}

Subcultures of each of the primary isolates were carried out on fresh L-J slopes and the resultant growths were again checked for purity and acid fast properties by microscopy.

Differentiation of isolates into human, bovine and other mycobacteria was based mainly on the abilities of the isolates to produce niacin or reduce nitrates to nitrites during growth. Classification of environmental isolates using Runyon's ${ }^{10}$ diagnostics scheme was done by testing all stains for rapidity of growth, pigment production and photochromogenesis. Strains growing in less than 7 days were classified as rapid growers while strains growing after 7 days were classified as slow growers. Photochromogens were classified as Runyon group 1, scotochromogens as group 3 and rapid growers as group 4.

Identification of the Runyon group 3 strains was based on the catalase activity of their broth cultures after heating at $68^{\circ} \mathrm{C}$ for 20 minutes. The ability to hydrolyse Tween 80 and reduce nitrate to nitrite was examined in group 1 isolates. For group 3 , isolates were screened mainly for their capability to reduce tellurite to tellurium within 3-4 days, while positivity for growth on MacConkey agar and the Arylsuphatase tests were used as differential tests in group 4 isolates.

A mycobacterium strain earlier identified as $M$. tuberculosis and a strain of $M$. fortuitum (NCTC 8573) were included in all the tests as positive and negative controls respectively.

\section{Statistical analysis}

The data obtained were subjected to the Chisquared test using a probability of $\mathrm{P}=0.05$ as the level of significance.

\section{RESULTS}

A total of 65 isolates of mycobacteria were obtained. The isolates and control organisms were subjected to all the various culture and biochemical tests and the results (Table 1). In terms of Runyon's groupings, none of the isolates gave positive reactions in the scotochromogenesis test and since tests were repeated several times with consistent results, it was taken that none belonged to Runyon's group 2.

Three of the isolates were positive in the photochromogenesis test, developing various shades of yellow to orange pigments after exposure to light. Three strains were classified as Runyon group 1 mycobacteria. The 62 non-chromogenic isolates were differentiated into rapid and slow growers on the basis of their growth rate on L-J slopes. Three isolates consistently showed visible, well matured colonies within 4-5 days of incubation. These isolates were taken as rapid growers and classified as Runyon group 4 strains. With the other isolates, growths on LJ slopes were observed after 10-14 days incubation and were therefore classified as slow growers.

Essentially all mycobacteria were catalase positive. Results from repeated tests were consistent and showed that while nine of the isolates still had catalase activities after the heat treatment, 50 were 
catalase negative. The nine catalase positive isolates were then classified as group 3 mycobacteria while the 50 negative isolates were assumed to be either M. tuberculosis or M. bovis. Ten of the 50 negative isolates were consistently negative in producing niacin and reducing nitrate to nitrite and were classified as $M$. bovis. The 40 isolates that produced niacin and reduced nitrate were classified as M. tuberculosis.

Table 1 Characterization of mycobacteria isolates/strain

\begin{tabular}{|c|c|c|c|c|c|c|c|}
\hline \multirow{2}{*}{$\begin{array}{r}\text { Tests } \\
\text { A. Culture }\end{array}$} & \multicolumn{5}{|c|}{ Isolates } & \multicolumn{2}{|c|}{ Controls } \\
\hline & & & & & & & \\
\hline Growth rate & $\mathrm{S}$ & $\mathrm{S}$ & $\mathrm{S}$ & $\mathrm{S}$ & $\mathrm{R}$ & $\mathrm{S}$ & $\mathrm{R}$ \\
\hline $\begin{array}{l}\text { Pigment produc- } \\
\text { tion (light) }\end{array}$ & & & - & + & - & - & \\
\hline $\begin{array}{l}\text { Pigment produc- } \\
\text { tion (dark) }\end{array}$ & - & - & - & - & - & - & _ \\
\hline Growth on Mac- & & & & & & & \\
\hline Conkey agar & - & - & - & - & + & - & + \\
\hline B. Biochemical & & & & & & & \\
\hline $\begin{array}{l}\text { Tween } 80 \text { hydroly- } \\
\text { sis (days) }\end{array}$ & $+(10)$ & - & - & - & - & $+(10)$ & - \\
\hline Arylsulphatase test & - & - & - & + & & - & - \\
\hline $\begin{array}{l}\text { Catalase test }\left(60^{\circ} \mathrm{C}\right. \\
\text { for } 20 \text { mins. })\end{array}$ & - & - & + & + & + & - & + \\
\hline Niacin production & + & - & - & - & - & + & - \\
\hline Tellurite reduction & - & - & + & - & - & - & + \\
\hline Nitrate reduction & + & - & - & - & - & + & - \\
\hline $\begin{array}{l}\text { Mycobacteria } \\
\text { strain identified }\end{array}$ & $\mathrm{a}$ & $\mathrm{b}$ & $\mathrm{c}$ & $\mathrm{d}$ & e & & \\
\hline Number of strains & 40 & 10 & 9 & 3 & 3 & & \\
\hline
\end{tabular}

Overall, of the 65 isolates $40(61.54 \%)$ were identified as $M$.tuberculosis, $10(15.38 \%)$ as $M$. bovis, $9(13.85 \%)$ as $M$. avium and $3(4.61 \%)$ each for $M$. kansasi and $M$. fortuition.

Table 2 shows the age and sex distribution of the identified cases with environmental and bovine mycobacteria.

Table 2 Age and sex distribution of cases with environmental and bovine mycobacteria

\begin{tabular}{ccccc}
\hline & \multicolumn{2}{c}{ Environmental } & \multicolumn{2}{c}{ Bovine } \\
Age (yrs) & Males & Females & Males & Females \\
\hline & & & & \\
$<15$ & - & - & - & - \\
$14-24$ & 2 & - & - & - \\
$25-34$ & 5 & 3 & 1 & 1 \\
$35-44$ & 2 & 1 & 4 & - \\
$45-54$ & 1 & 1 & 2 & - \\
$55-64$ & - & - & 2 & - \\
$<65$ & - & - & - & - \\
\hline Total & $\mathbf{1 0}$ & $\mathbf{5}$ & $\mathbf{9}$ & $\mathbf{1}$
\end{tabular}

\section{DISCUSSION}

The involvement of environmental mycobacteria strains in human pulmonary infection in the developed and developing countries has been frequently reported. In these papers, incidence rates of $2-10 \%$ for atypical mycobacteria were noted ${ }^{4,5,11,12}$. Data in the present study confirms the involvement of environmental mycobacteria in human pulmonary infection in Jos. An incidence rate of $23.08 \%$ for human atypical mycobacteriosis reported for various parts of the world ${ }^{6,7}$ but lower than the prevalence rate of $26.6 \%$ for atypical tuberculoid bacilli earlier reported by Allanana et $\mathrm{al}^{12}$ in Jos. Strains of $M$. kansasii, M. avium and $M$. fortuitum were isolated from various patients within the period. Idigbe et $\mathrm{al}^{13}$ in a report from Lagos not only confirmed the involvement of atypical mycobacteria in human infections but indicated a progressive increase in the prevalence of atypical mycobacteria from $14.6 \%$ in 1982 to $30.1 \%$ in 1992. Again, strains of M. kansasii, M. avium, M.fortuitum and $M$. xenopi were isolated from various patients. The resurgence of tuberculosis worldwide has been attributed to the rising prevalence of HIV/AIDS. At the end of 2001, an estimated 40 million people globally were living with HIV according to the Joint United National Programme on HIV/AIDS ${ }^{14}$. In Nigeria, a prevalence rate $5 \%$ was documented within the period ${ }^{15}$.

However, despite this involvement of atypical mycobacteria, results from this study have incriminated $M$.tuberculosis as the most prevalent causative agent of the cumulative number of positive TB cases detected in Jos. This situation is not different from earlier reports by Allanana et $\mathrm{al}^{12}$ in Jos, Idigbe et $\mathrm{al}^{13}$ in Lagos and some other parts of the world $^{16}$.

Isolation of species of atypical mycobacteria from patients in this study suggests the pathogenic role of such atypical mycobacteria in these patients. The most important feature of atypical mycobacteria is the ability of some of them to produce tuberculosis-like disease frequently resistant to usual tuberculosis therapy ${ }^{17,18}$. In most of Nigeria and other developing countries, diagnosis of tuberculosis is usually based on such symptoms as fever, loss of weight, persistent productive cough, haemoptysis and an abnormal chest X-ray. Where laboratory facilities are available the presence of acid fast bacilli in clinical specimens is also used in diagnosis. However, observations from this study and several other studies seem to further highlight the increasing awareness that the presence of acid fast bacilli in sputum, X-ray abnormality or mere 
isolation of mycobacterium colonies on L-J slopes is not enough to establish a case of classical pulmonary tuberculosis. Identification of the mycobacterium isolate is inevitably necessary.

A significant observation in this study was that all the 15 cases of atypical mycobacteriosis before bacteriological identification of the isolates were queried as pulmonary tuberculosis (PTB) and sent to the laboratory for AFB microscopy. A positive AFB microscopy result and other relevant clinical data would result in the patients being placed on anti-tuberculosis regimens. This result in most of the cases would have been little or no response to therapy after prolonged treatment.

Evidence from the study also indicated the involvement of bovine mycobacteria in human pulmonary infections in Jos. An prevalence of $15.4 \%$ was documented.

Other reports of the involvement of bovine mycobacteria in human pulmonary infections in Nigeria were those of Alhaji and Schurrenberger8 who documented a $10 \%$ incidence rate in four of the Northern States of the country and Idigbe et $\mathrm{al}^{5}$ who reported a $3.9 \%$ incidence rate of bovine mycobacteriosis in Lagos. Results of the present study in the Northern part of Nigeria revealed a prevalence rate of $15.4 \%$ for bovine mycobacteriosis. Thus, it would appear that the prevalence of bovine mycobacteriosis is higher in the Northern than the Southern part of the country.

A more detailed epidemiological survey of various parts of the country would be needed to confirm this observation. However, it is likely that the hypothesis could be correct because culturally a significant proportion of the Northern population are nomadic pastoralist and thus have more frequent contact with domestic animals than the Southern population. Several workers have associated bovine mycobacteriosis with cattle ${ }^{17,19}$.

\section{REFERENCES}

1. Beer AG and Davis GHG. Anonymous mycobacteria isolated in Lagos, Nigeria. Tubercle 1965; 46: 32-39.

2. Krivinka R, Drapea J, Kubic A, Dankova D, Krivanek J, Ruzaa J, Mikova W, HedJova E. Epidemiology and clinical study of tuberculosis in the district of Kolin, Czechoslovakia. Bull of WHO 1974; 51:69-73.
3. Lornado M, isola NV, Ambroggi M, Fulldosa G, de Kantor IN. Non-tuberculosis mycobacteriosis in Buenos Aires, Argentina. Bull of IUAT 1982; 57(1): 55-59.

4. Jenkins PA. Five years experience of a simple system for identification of mycobacteria. Bull of Intl Union against Tuberc 1982; 57(1): 5658.

5. Idigbe EO, Anyiwo CE, Onwujekwe DI. Human pulmonary infection with bovine and atypical mycobacteria in Lagos, Nigeria. $J$ of Trop Med and Hyg 1986; 89: 143-148.

6. Koitan N, Ganesan V, SarVamangala JG, Achyutha KN. Pulmonary infections by atypical mycobacteria in a rural coastal region of Kranataka, India. Trop and Geograph Med 1981; 33: 117-121.

7. Grosset $\mathrm{J}$ and Truffot-Pernot $\mathrm{C}$. The bacteriology of tuberculosis. Bull of Intl Union against Tuberc 1982; 57(3/4): 226-228.

8. Alhaji I and Schnurrenberger P. Public health significance of bovine tuberculosis in four Northern States of Nigeria. A mycobacteriological study. Nigerian Med J 1977; 7(4): 384-386.

9. Cruickshank R, Duguid JP, Marmion B, Swain RHA. Medical Microbiology, Churchill Livingstone, London. 1975; 2: 562.

10. Runyon EH. Anonymous mycobacteria in pulmonary disease. Med Clin of Northern America 1959; 43: 273-278.

11. Nunn P, McAdam KPJW. Mycobacteria infection in AIDS. Bri Med Bull 1988; 44: 801804.

12. Allanana JA, Ikeh EI, Bello CSS. Mycobacterium species from clinical specimens in Jos, Nigeria. Nigerian J of Med 1991; 2(1-2): 111112 .

13. Idigbe EO, Sofola JO, John EKO, Okoye R, Onugbogu C, Begg O, Giwa-Amu J. The trend of pulmonary tuberculosis in Lagos, Nigeria 1982-1993. Biomed Letters 1995; 55: 99-109.

14. Joint United Nations Programme on HIV/AIDS. AIDS epidemic updates. 
www.unaids.org/epidemicup-date/reportdeco/index.html, 2002.

15. Federal Ministry of Health (FMOH). 2003 HIV sero-prevalence sentinel survey. Technical report on the 2003 national HIV/syphilis sentinel survey among pregnant women attending antenatal clinics in Nigeria. 2004; $1-$ 44.

16. World Health Organisation. Tuberculosis and AIDS: global programme on AIDS and tuberculosis programme. WHO in collaboration with IUAT and LD. Bull of Intl Union against Tuberc \& Lung Dis 1989; 64: 8-11.
17. American Thoracic Society. The official joint statement of the American Thoracic Society and Centre for Disease Control on the treatment of tuberculosis and other mycobacteria disease. US Department of Health and Human Services, Atlanta 1982; 343-358.

18. Grange JM. Bacteriology of tuberculosis. Postgrad Doc 1984; 6(10): 304-309.

19. Leslie IW, Magnus K, Steward CJ. The prevalence of bovine type of tuberculosis infection in man in the English population. Tubercle 1972; 53: 198-292. 